\title{
Experimental Assessment of First- and Second-Life Electric Vehicle Batteries: Performance, Capacity Dispersion and Aging
}

\author{
Elisa Braco, Idoia San Martín, Alberto Berrueta, Pablo Sanchis, Alfredo Ursúa \\ Department of Electrical, Electronic and Communication Engineering \\ Institute of Smart Cities \\ Public University of Navarre \\ Pamplona, Spain \\ alfredo.ursua@unavarra.es
}

\begin{abstract}
Nowadays, the reuse of electric vehicle batteries is considered to be a feasible alternative to recycling, as it allows to benefit from their remaining energy capacity and to enlarge their lifetime. Stationary applications, such as self-consumption or off-grid systems support, are examples of second-life (SL) uses for retired batteries. However, reused modules that compose these batteries have heterogeneous properties, which limit their performance. This paper aims to assess the influence of degradation in modules from electric vehicles, covering three main aspects: performance, capacity dispersion and extended SL behavior. Firstly, a complete characterization of new and reused modules is carried out, considering three temperatures and three discharge rates. On a second stage, intra- and inter-module capacity dispersion is evaluated with new and reused samples. Finally, the behavior during SL is also analyzed, through an accelerated cycling test so that the evolution of capacity and dispersion are assessed. Experimental results show that the performance of reused modules is specially undermined at low temperatures and high current rates, as well as in advanced stages of aging. The intra-module dispersion is found to be similar in reused and new samples, while the inter-module differences are nearly four times greater in SL.
\end{abstract}

Keywords-Electric vehicle, Energy storage, Lithium-ion battery, Renewable energy, Second-life batteries, Characterization.

\section{INTRODUCTION}

Environmental problems caused by fossil fuels are placing the Electric Vehicle (EV) as an alternative for sustainable mobility. As reported by the International Energy Agency, the total number of EVs in the world reached 5.1 million in 2018 [1]. According to this source, this figure will continue to rise up to 130 million by 2030 .

One of the most critical elements of EVs are their Li-ion batteries (EVB). The performance of EVBs undermines with aging, due to multiple factors, such as temperature, charge and discharge current rate or voltage operation limits, inter alia. For this reason, automotive regulations establish the end of the useful life of EVBs when their capacity falls below 70 to $80 \%$ of the initial value [2], [3]. As opposed to the traditional alternative of recycling, discarded EVBs can be reused in other applications, thereby extending their lifetime. It is in this context that the Second Life (SL) concept becomes relevant, being related to the post-EV use, in contrast to the so-called First Life (FL), in which they serve as energy storage device in the EV.

This work has been supported by the Spanish State Research Agency (AEI) under grants PID2019-111262RB-I00 /AEI/ 10.13039/501100011033 and DPI2016-80641-R, the European Union under the H2020 project STARDUST (774094), the Government of Navarra through research project 0011-1411-2018-000029 GERA and the Public University of Navarre under project ReBMS PJUPNA1904.
The SL of EVBs benefits from their remaining energy capacity for less demanding applications, in which power and energy density are not as key as in EVs. This entails economic and environmental advantages, such as a potential reduction of up to $20 \%$ in the upfront costs of EVs due to the salvage value of their batteries [4], [5]. The reuse of EVBs has aroused industrial and research interest in recent years [6]-[8]. From the industrial point of view, the potential of SL EVBs is especially appealing for automotive companies such as Nissan [9], BMW [10] or Daimler [11], which, in partnership with energy companies, have built large-scale demonstrators. One of the most promising SL applications is residential storage facilities with photovoltaic installations [12], where FL Li-ion batteries are normally used as storage systems [13]-[16]. In the years to come, the SL storage market is expected to grow as a result of the expansion of EVs, reaching 26 GWh by 2025 [17].

Nevertheless, there are still many uncertainties regarding economic and technical viability of SL EVBs [8], [18]. In recent years, research contributions have focused on their economic [19], [20] and technical assessment considering different SL applications, such as renewable energy integration [21], residential demand [22] or isolated microgrids [23]. The economic viability of reused EVBs is highly influenced by their performance and durability. On the one hand, the performance of a battery is determined by the internal parameters of its cells, namely capacity and internal resistance. The initial variability of these parameters, which is a consequence of diverse factors such as manufacturing processes, is aggravated by the operating conditions of the cells, therefore increasing during aging [24]-[26]. This heterogeneity affects the performance of the whole battery, as they may compromise the accuracy of SOC estimators [27], the requirements for power converters [28] or even battery lifetime [29], [30]. The necessity of proper characterization and adequate cell selection to decrease the impact of heterogeneity have been stated by several contributions as key to certify SL EVBs technical viability [30], [31]. On the other hand, the durability of reused cells has been suggested to be determined by the change in their aging rate [31], [32].

The drawbacks of reused EV modules compared to their new counterparts regarding performance and dispersion have been identified as a relevant issue in previous research work [33]. Other contributions have analyzed the heterogeneity of SL batteries with laboratory-aged cells [31] or compared FL and SL cells with different chemistries and capacities [24]. However, the analysis of real SL EVBs and their comparison with similar brand-new homologues is seldom reported in literature. Therefore, this contribution aims to cover this gap, by assessing the influence of degradation on new and retired 
modules from Nissan Leaf EVs through experimental procedures. More precisely, it focuses on three aspects: performance, capacity dispersion and extended SL behavior.

The paper is organized as follows: Section II describes the modules under analysis and the experimental procedure. Section III offers a detailed characterization of FL and SL modules considering three temperatures and three test currents. From its part, Section IV presents an intra-module and intermodule dispersion analysis for new and reused samples. Finally, Section $\mathrm{V}$ focuses on SL performance during aging by means of accelerated cycling tests.

\section{EXPERIMENTAL SETUP}

\section{A. Module description}

The modules analyzed in this contribution were specially designed for EV, in particular for the Nissan Leaf model. Each module is composed of four pouch-type cells of manganese oxide/graphite (LMO/C), associated in two parallel-connected pairs in series (2s2p), as it is shown in Fig. 1a. The modules have three terminals: positive $(\mathrm{R})$, middle point $(\mathrm{W})$ and negative (B). We will call in this paper superior pair and inferior pair cells to the $2 p$ cells connected between $\mathrm{R}$ and $\mathrm{W}$, and between $\mathrm{W}$ and $\mathrm{B}$ respectively. Therefore, the superior pair cells and inferior pair cells are accessible, as Fig. 1b depicts. The main specifications of the modules are compiled in Table I.

The experimental assessment of this contribution has been carried out with $42 \mathrm{EV}$ modules. On the one hand, 32 modules came from real EV battery packs, and were discarded since they had reached the end of their automotive useful life. The aging history of these modules, e.g. driving mileage or operating conditions is unknown, given that the company does not provide such information nowadays. On the other hand, 10 similar modules are brand-new and have not been tested beforehand. Hereafter they will be called SL and FL modules respectively.

\section{B. Experimental procedure description}

This work assesses the impact of degradation in operation and capacity dispersion of EV modules, as well as their be- a)

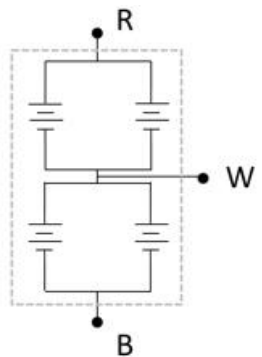

b)

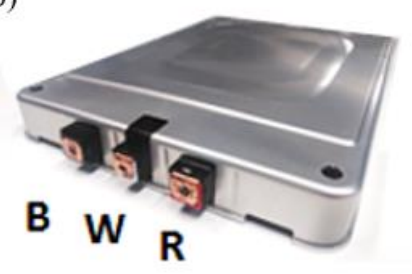

Fig. 1.a) Internal module scheme and b) Nissan Leaf module picture.

TABLE I. MODULE SPECIFICATIONS

\begin{tabular}{|l|c|}
\hline & Module \\
\hline Nominal Voltage & $7.5 \mathrm{~V}$ \\
\hline Maximum Voltage & $8.3 \mathrm{~V}$ \\
\hline Minimum Voltage & $5 \mathrm{~V}$ \\
\hline Rated Capacity & $66 \mathrm{Ah}$ \\
\hline Length x Width x Thickness & $303 \mathrm{~mm} \mathrm{x} 223 \mathrm{~mm} \times 35 \mathrm{~mm}$ \\
\hline Mass & $3.85 \mathrm{~kg}$ \\
\hline
\end{tabular}

havior during SL. Therefore, three main experimental procedures are carried out: characterization tests, capacity measurements and cycle aging tests.

On the one hand, the influence of the current rate (C-rate) and temperature on a FL and on a SL module is analyzed through a detailed characterization of their electrical behavior. For this purpose, the modules are tested on their superior pair cells. Three testing temperatures are considered: $5^{\circ} \mathrm{C}, 25^{\circ} \mathrm{C}$ and $45^{\circ} \mathrm{C}$. The selection of these levels allows to cover a wide range of feasible operating temperatures of SL applications without risk of additional aging mechanisms, such as Li plating at low temperatures [34], or of thermal runaway at high temperature values. For each temperature, three C-rates are tested: $0.5 \mathrm{C}, 1 \mathrm{C}$ and $1.5 \mathrm{C}$. The C-rate is defined as $66 \mathrm{~A}$, which corresponds to the rated capacity of a new module (see Table I). The test starts with a rest period at the desired temperature, so that cells reach thermal equilibrium. The cell pair is then discharged with a Constant Current (CC) at $0.5 \mathrm{C}$ to the minimum cell voltage. A set of six full cycles are then performed, in such a way that the discharge C-rate is changed every two cycles. Given the reused character of the modules, the number of repetitions is set so that the impact of aging does not compromise the accuracy of the characterization results. The charging method applied is Constant Current - Constant Voltage (CC-CV) at $0.5 \mathrm{C}$, with $\mathrm{C} / 30$ as end current on the $\mathrm{CV}$ phase. $\mathrm{CC}$ discharges are performed at the corresponding $\mathrm{C}$ rate to the minimum cell voltage. Note that the maximum and minimum cell voltage are half of the values presented for a module in Table I.

On the other hand, the capacity test consists of a sequence of five cycles with $\mathrm{CC}-\mathrm{CV}$ charges and $\mathrm{CC}$ discharges between the maximum and minimum cell voltages. The $\mathrm{C}$-rate on the $\mathrm{CC}$ phase is $\mathrm{C} / 3$, and the end current on the $\mathrm{CV}$ stage is set to $\mathrm{C} / 30$. The capacity of the cell is considered as the discharge capacity measurement of the fifth cycle. All the modules are tested on the superior and inferior pair cells at $25^{\circ} \mathrm{C} \pm 1{ }^{\circ} \mathrm{C}$.

Furthermore, a set of 6 SL modules are considered for extended cycle aging tests. The selected aging profile consists of a sequence of full cycles with $\mathrm{CC}-\mathrm{CV}$ charge and $\mathrm{CC}$ discharge between the cell voltage limits. The $\mathrm{CC}$ stages are performed at $1 \mathrm{C}$, and the cutoff current of the $\mathrm{CV}$ phase is $\mathrm{C} / 20$. The test is carried out in the superior pair cells at $25^{\circ} \mathrm{C} \pm 1{ }^{\circ} \mathrm{C}$.

The test bench used for the experimental procedures of this contribution is shown in Fig. 2. It consists of three battery testers with 16 channels, each channel standing $5 \mathrm{~V}$ and $50 \mathrm{~A}$, as well as two climatic chambers with temperature range from $30{ }^{\circ} \mathrm{C}$ to $180^{\circ} \mathrm{C}$. The voltage and current precision of the battery testers is $\pm 0.1 \%$ of the full scale, while the climatic chambers have a temperature control precision of $\pm 0.5^{\circ} \mathrm{C}$.

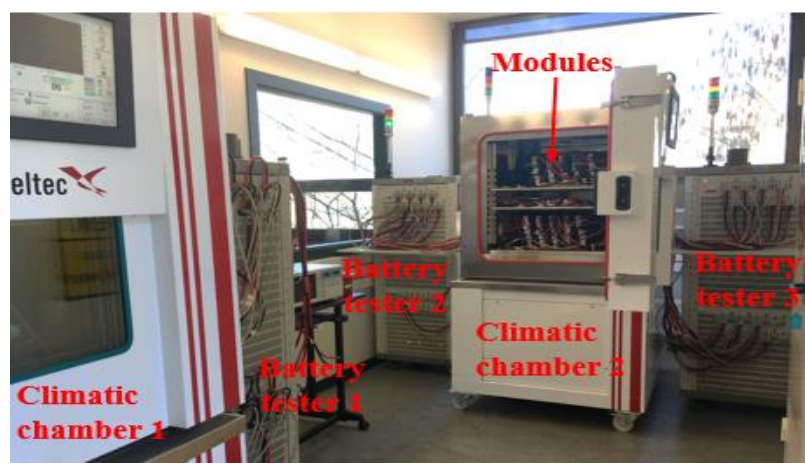

Fig. 2. Test bench used for the experimental procedures. 


\section{CHARACTERIZATION}

Capacity and power fade are two consequences of battery aging that are strongly influenced by the operating conditions. Several factors, such as temperature, state of charge, charge and discharge current or depth of discharge, among others, have impact on batteries performance and aging. Specifically, this section is focused on the influence of two of these parameters, namely temperature and discharge current, on a FL and on a SL module. For this purpose, three discharge rates $(0.5 \mathrm{C}$, $1 \mathrm{C}$ and $1.5 \mathrm{C})$ and three operating temperatures $\left(5^{\circ} \mathrm{C}, 25^{\circ} \mathrm{C}\right.$ and $45^{\circ} \mathrm{C}$ ) are tested as described in Subsection II.B. The influence of these parameters on capacity and energy efficiency is firstly presented in this section, and on a second stage the impact of degradation on performance under the different operating conditions is analyzed. Moreover, energy and power per mass unit are assessed in both FL and SL modules.

\section{A. Influence of current and temperature on capacity and on energy efficiency}

As an indicator of the energy storage capabilities of a battery, capacity is a parameter of great interest regarding the influence of the operating conditions during battery lifetime. Therefore, this subsection examines up to what extent the energy capabilities of the modules vary at various aging states and under different temperatures and loads. From the characterization test described in Subsection II.B, capacity is measured for a given temperature and discharge current in the superior cell pairs. The results obtained for the FL and the SL module are presented in Table II. All the capacity data are provided in Ah.

In order to compare the results in relative terms, Fig. 3 depicts the capacity measurements normalized with respect to the current capacity of the superior cell pairs, measured at $25^{\circ} \mathrm{C}$ and with a discharge rate of $\mathrm{C} / 3\left(C_{r e f}\right)$, for the three temperature levels $\left(5^{\circ} \mathrm{C}, 25^{\circ} \mathrm{C}\right.$ and $\left.45^{\circ} \mathrm{C}\right)$ and discharge current rates $(0.5 \mathrm{C}, 1 \mathrm{C}$ and $1.5 \mathrm{C})$ tested. More precisely, the current capacities of the superior cell pairs in the SL and the FL modules are 43.5 $\mathrm{Ah}$ and 64.2 $\mathrm{Ah}$ respectively. Both results are lower than the rated capacity value (see Table I). Considering the SL sample, this difference is mainly due to its EV usage during its first life, while in the new cells the capacity fade could be principally related to calendar aging phenomena occurred since the module was manufactured.

From the experimental results, the influence of discharge current on capacity measurements is noted to be especially relevant at low temperatures and in the case of the SL module. While at $45^{\circ} \mathrm{C}$ the capacity measurements in this sample differ $3 \%$, at $5^{\circ} \mathrm{C}$ up to $18 \%$ of variation was observed. From its part, the FL module shows similar data for all the tested temperatures, with differences lower than $2 \%$. On the other hand, temperature has greater impact at high discharge rates. Once again, the greatest measurement variation is observed in the SL module, with $24 \%$ at $1.5 \mathrm{C}$. As in the previous case, the

TABLE II. CAPACITY MEASUREMENTS IN A FL AND A SL MODULE $(\mathrm{AH})$

\begin{tabular}{|c|c|c|c|c|c|c|}
\hline & \multicolumn{3}{|c|}{ SL module } & \multicolumn{3}{c|}{ FL module } \\
\hline & $\begin{array}{c}0.5 C \\
(22 \mathrm{~A})\end{array}$ & $\begin{array}{c}1 C \\
(66 \mathrm{~A})\end{array}$ & $\begin{array}{c}1.5 C \\
(99 \mathrm{~A})\end{array}$ & $\begin{array}{c}0.5 C \\
(22 \mathrm{~A})\end{array}$ & $\begin{array}{c}1 C \\
(66 \mathrm{~A})\end{array}$ & $\begin{array}{c}1.5 \mathrm{C} \\
(99 \mathrm{~A})\end{array}$ \\
\hline $5^{\circ} \mathrm{C}$ & 38.1 & 36.4 & 31.3 & 62.1 & 61.8 & 61.5 \\
\hline $25^{\circ} \mathrm{C}$ & 42.3 & 41.7 & 41.2 & 63.7 & 63.4 & 63.2 \\
\hline $45^{\circ} \mathrm{C}$ & 42.6 & 41.8 & 41.3 & 64.6 & 64.1 & 63.8 \\
\hline
\end{tabular}

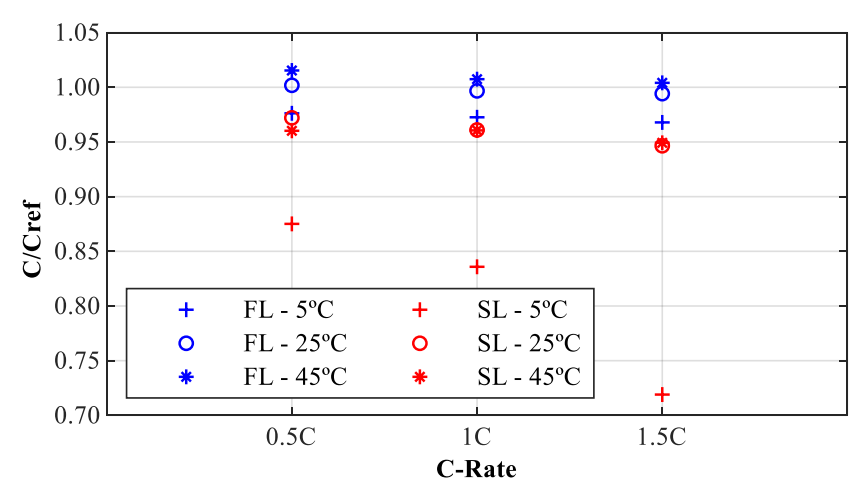

Fig. 3. Normalized capacity depending on discharge C-rate for different temperatures $\left(5^{\circ} \mathrm{C}, 25^{\circ} \mathrm{C}\right.$ and $\left.45^{\circ} \mathrm{C}\right)$ for a $\mathrm{FL}$ and a SL module.

deviations observed in the FL module are considerably lower, up to $4 \%$ for all the discharge rates.

As Fig. 3 shows, the lowest capacity measurement corresponds to $1.5 \mathrm{C}$ and $5{ }^{\circ} \mathrm{C}$ for both modules. This may be due to the reduction of electrolyte viscosity and ion transport properties associated to performance of Li-ion cells at low temperatures [35], together with the decrease of accessible capacity of a Li-ion cell as the discharge rate increases [36]. Nevertheless, the impact on capacity differs, as the lowest value obtained in the FL module is $95 \%$ of $C_{r e f}$, whereas in the SL module it decreases to $72 \%$.

When it comes to real applications, the performance of the modules is determined not only by their capacity, but also by their internal resistance. Therefore, other indicators, such as energy efficiency, are used to evaluate modules operation. With a view to deepen the characterization analysis, the impact of discharge current and temperature on energy efficiency is also discussed in this subsection. This parameter is computed as the ratio between discharge and charge energy of a given cycle under specified conditions. Fig. 4 depicts the results of energy efficiency obtained from the characterization test described in Section II for the three discharge currents and temperatures under study in both modules.

As it can be seen in the figure, the influence of temperature on energy efficiency is particularly noticeable at high discharge currents. However, the SL module is much more affected, as the maximum variation reported at $1.5 \mathrm{C}$ is $22 \%$, in contrast to $5 \%$ in the FL module. On the other hand, considering the influence of the discharge current for a given temperature, both modules show peak differences at $5{ }^{\circ} \mathrm{C}$. The SL module is once again much more affected, reaching $21 \%$ of variation compared to $5 \%$ measured in the FL sample. Regarding absolute values of energy efficiency, the results obtained in the

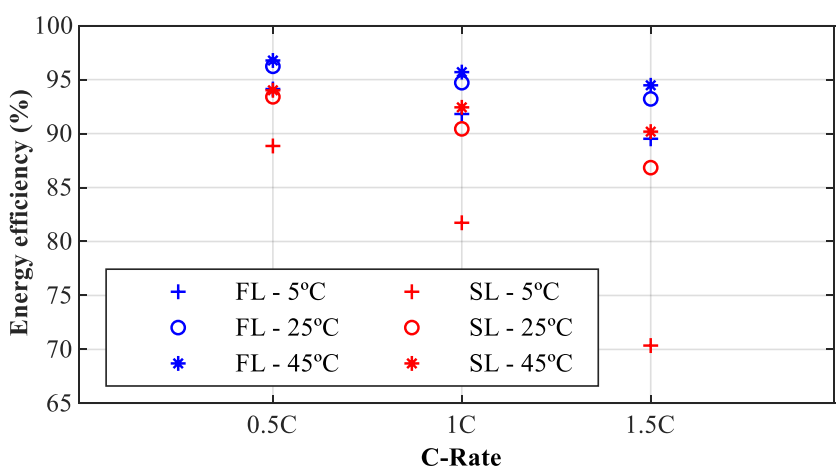

Fig. 4. Energy efficiency depending on discharge C-rate for different temperatures $\left(5^{\circ} \mathrm{C}, 25^{\circ} \mathrm{C}\right.$ and $\left.45^{\circ} \mathrm{C}\right)$ for a $\mathrm{FL}$ and a SL module. 
FL module range from $89 \%$ to $97 \%$, while in the SL module the efficiency varies between $70 \%$ and $94 \%$. In both cases the lowest datum is obtained at $5^{\circ} \mathrm{C}$ and $1.5 \mathrm{C}$.

\section{B. Influence of degradation on module performance}

Batteries operation is generally set according to voltage limits defined by the manufacturer. Nevertheless, as battery ages, its response to current changes varies due to the increase of its internal resistance, an effect that is more evident at high current rates. The reduction of the battery performance range affects directly to the energy that it can provide. In this context, this subsection analyzes the influence of temperature and discharge current rates on the operation voltage for the FL and SL modules. Fig. 5 shows the discharge voltage measured on the characterization test for $0.5 \mathrm{C}, 1 \mathrm{C}$ and $1.5 \mathrm{C}$ rates for $45^{\circ} \mathrm{C}$ (Fig. 5a), $25^{\circ} \mathrm{C}$ (Fig. 5b), and $5^{\circ} \mathrm{C}$ (Fig. 5c) in the FL and SL modules. The corresponding discharge capacity is plotted in the $\mathrm{X}$ axis.

As it is shown in Fig. 5, the discharge voltage in the FL module is similar for the three temperatures tested, but some polarization effect can be observed. In a real application, this polarization may become a significant factor, as it leads to efficiency reduction and greater thermal power dissipation. In order to quantify this effect, the performance of the modules
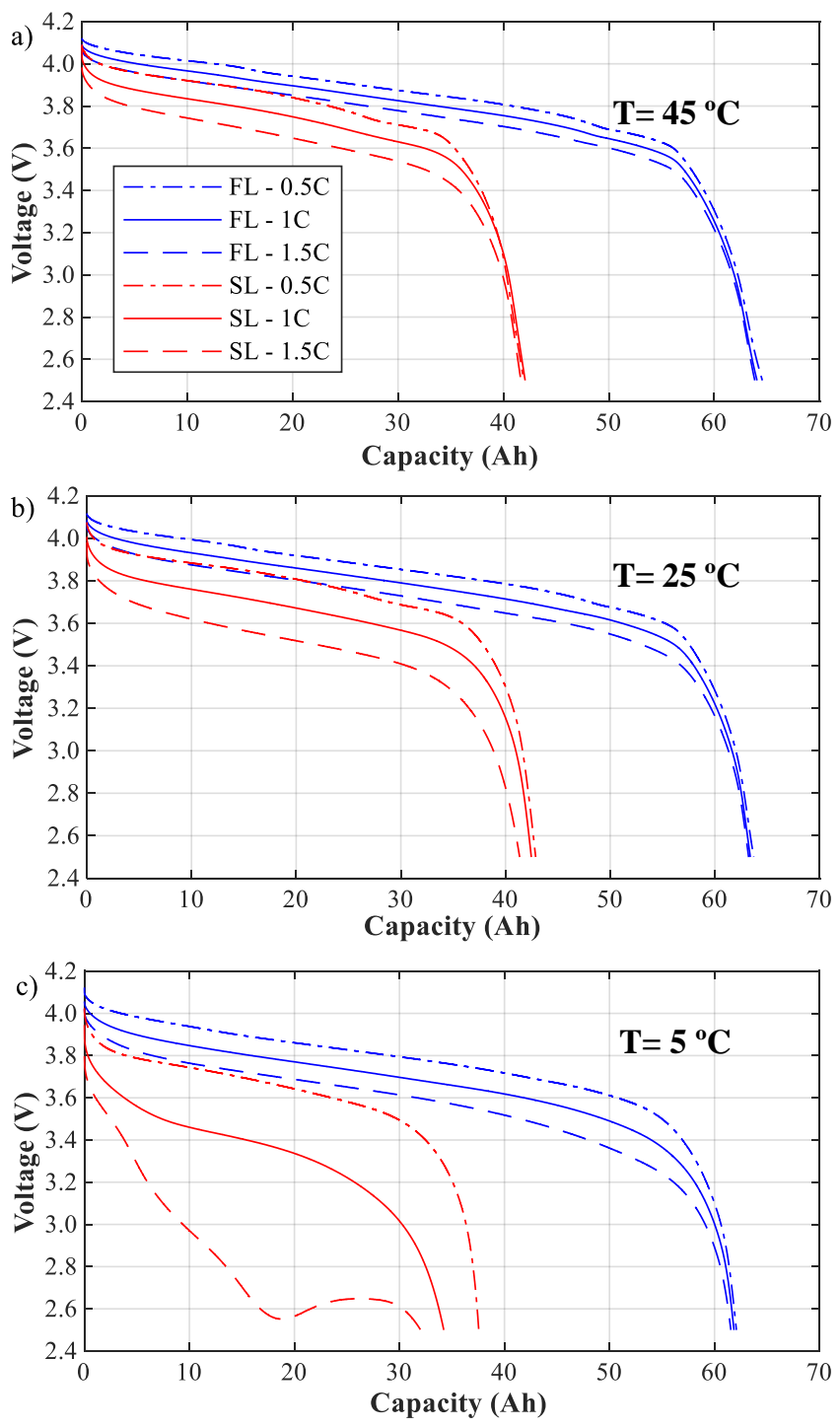

Fig. 5. Discharge voltage vs. capacity for a FL and SL modules at $0.5 \mathrm{C}$, $1 \mathrm{C}$ and $1.5 \mathrm{C}$ for a) $45^{\circ} \mathrm{C}$ b) $25^{\circ} \mathrm{C}$ and c) $5{ }^{\circ} \mathrm{C}$ as test temperatures. is compared between $1.5 \mathrm{C}$ and $0.5 \mathrm{C}$ at a typical SOC of $50 \%$, so that the results are representative of other SOC levels. Hence, the largest voltage drop is $180 \mathrm{mV}$, measured at $5^{\circ} \mathrm{C}$. On the other hand, the lowest result, $100 \mathrm{mV}$, is observed at $45^{\circ} \mathrm{C}$. These differences are related to the internal resistance of the module, which in Li-ion batteries is normally lower at high temperatures. Furthermore, in all cases the voltage drop is greater in the SL module. More precisely, results vary from $190 \mathrm{mV}$ at $45^{\circ} \mathrm{C}$ up to $1.02 \mathrm{~V}$ at $5^{\circ} \mathrm{C}$, which imply almost six times the voltage difference measured in the FL module at this last temperature. These findings confirm that the internal resistance of a module has a greater impact in reused modules. The discharge voltage of the SL module at $5{ }^{\circ} \mathrm{C}$ even shows a different shape, with a greater initial slope and an intermediate knee. The fast voltage drop measured at the beginning of the test is due to the slower diffusion phenomena occurring at low temperatures. After a few minutes of high-current operation, the internal temperature of the module rises, thereby improving the ion diffusion, which leads to the measured voltage recovery between 20 and 35 Ah in Fig. 5c.

When it comes to real applications, the lower voltage limit is usually raised at low temperatures for security purposes. From the results obtained, it could be argued that this limit would have a great impact in the energy delivered by the SL modules at high discharge rates. For instance, if the lower voltage limit is set to $3 \mathrm{~V}$, the energy provided at $1.5 \mathrm{C}$ and $5^{\circ} \mathrm{C}$ would be $76 \%$ lower than at $25^{\circ} \mathrm{C}$ for the same current. However, at $0.5 \mathrm{C}$ the reduction would be $6 \%$. From its part, the FL module delivers around $3 \%$ less energy at $5{ }^{\circ} \mathrm{C}$ than at $25^{\circ} \mathrm{C}$ for both currents.

\section{Specific energy and power}

In addition to the power and energy capabilities of a battery, their correlation with its mass is of great interest from the application point of view. The modules of this contribution are especially designed for the automotive sector, so they have high specific power and energy. However, these features are degraded as a consequence of their FL history. Hence, this subsection examines the impact of temperature and current on the power and energy of FL and SL modules, evaluating data per mass unit.

The delivered energy for a given temperature and current is computed from the corresponding discharge measurement of the second cycle of the characterization test described in Section II. By dividing this energy value by the discharge time, the power is obtained. Both discharge energy and power are divided by half the mass of the module, thus computing the equivalents per mass unit. Fig. 6 depicts the experimental results obtained for a SL and a FL module regarding power and energy per unit mass for the three temperatures and currents tested.

As it is shown in the figure, temperature influences energy more than power for a given discharge current. This effect is especially noticeable at high C-rates, and it affects much more the SL module. The maximum variations in this sample at $1.5 \mathrm{C}$ are $39 \%$ in energy and $20 \%$ in power, while in the FL module only $8 \%$ and $4 \%$ of differences are observed respectively. On the other hand, discharge C-Rate has greater influence in power than in energy, which is especially remarkable at extreme currents and low temperatures. Once again, the differences observed in terms of energy are greater in the SL module, reaching $32 \%$ at $5{ }^{\circ} \mathrm{C}$, against $6 \%$ in the FL module. Nevertheless, the differences observed in power measurements of both samples are similar, with maximum values of 


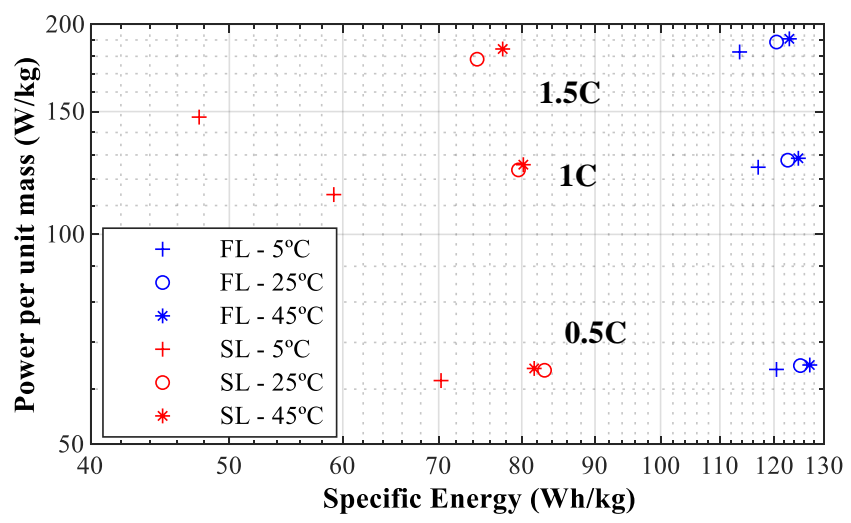

Fig. 6. Discharge power vs. discharge energy per mass unit, for a FL and SL modules at $5{ }^{\circ} \mathrm{C}, 25^{\circ} \mathrm{C}$ and $45^{\circ} \mathrm{C}$, for $0.5 \mathrm{C}, 1 \mathrm{C}$ and $1.5 \mathrm{C}$ as test discharge currents.

$67 \%$ and $65 \%$ in the SL and FL module respectively. This shows that even though the voltage response of a cell is likely to change with aging, capacity loss has a greater impact on the performance of degraded cells. Therefore, the differences in the energy capabilities between new and reused modules are greater than in terms of power.

Comparing the performance of both modules, the maximum differences are related to high currents and low temperatures. More precisely, the SL module has a specific energy and power loss of $58 \%$ and $19 \%$ respectively compared to the FL module. This result is consistent with the variations in capacity measurements observed in Section III.A. Nevertheless, it should be noted that the applications considered for reused modules are usually stationary, and therefore the consequences of these differences are not critical.

\section{DISPERSION ANALYSIS}

Even though the withdrawn limit for EVBs is $70 \%$ to $80 \%$ of their initial capacity, the real values of this parameter at the beginning of their SL may differ due to the different aging trends. Quantifying this heterogeneity becomes key at the reconfiguration stage, where economic and technical balance determines the reassemble at cell or module level. This section is thus focused on the analysis of capacity dispersion on 32 SL modules and 10 FL modules from Nissan Leaf EVs. The internal dispersion (intra-module) of the module is first presented and, in a second step, the dispersion among modules (inter-module) is evaluated. All the capacity measurements are carried out according to the capacity test described in Section II.

\section{A. Intra-module dispersion}

The quantification of the internal dispersion of retired modules allows to determine to what extent disassemble is worthwhile, given the complexity and cost of this procedure. This subsection aims to assess experimentally the internal dispersion in terms of capacity of the Nissan Leaf modules, both in FL and SL.

As explained in Section II, each module consists of four cells in a 2 s $2 p$ assembly and has three external terminals (see Fig. 1). The capacity test is carried out in both $2 p$ superior cells and 2 p inferior cells. Fig. 7 a shows the capacity measurements of the superior and inferior cells on the 32 SL modules, whereas Fig. $7 \mathrm{~b}$ represents the absolute capacity differences between superior $\left(C_{s}\right)$ and inferior $\left(C_{i}\right)$ cells normalized by the average capacity of each module $\left(C_{m}\right)$. The maximum intramodule difference is $1.5 \mathrm{Ah}$, measured in module 28 , which implies $3.4 \%$ of variation with respect to its average capacity. Conversely, the lowest difference observed corresponds to $0.05 \%$ in module 32 .

On the other hand, Fig. 8 presents the existing dispersion on 10 FL modules. Fig. 8a shows superior and inferior cells capacity of each tested module, and Fig. $8 \mathrm{~b}$ plots absolute capacity differences between superior and inferior cells, with respect to each module average capacity. The greatest differences are observed in module 5 , with a difference with respect to the mean capacity of $2.3 \%$. The lowest difference, less than $0.01 \%$, is observed in module 6 , in which superior and inferior cells capacities are almost equal.

From the experimental measurements of this subsection, it can be stated that even if the cells that constitute a module are not identical, their differences are not significant. Hence, the position inside the module does not influence the aging history of the cells. Moreover, given the high cost of modules disassembling, this heterogeneity is considered to be assumable on the SL batteries reconfigured from these modules.

\section{B. Inter-module dispersion}

Another SL reconfiguration option is reassembling at module level. Since this alternative is more complex and expensive than the direct usage of battery packs, the quantification of the existing differences between modules is also interesting for the remanufacturing agents. In this context, this subsection compares the capacity data of 32 SL and 10 FL modules, so that the inter-module dispersion is defined. Given that the superior and inferior cell pairs are associated in series, module capacity will be defined as the lowest capacity value of both pairs, according to data presented in the previous subsection.
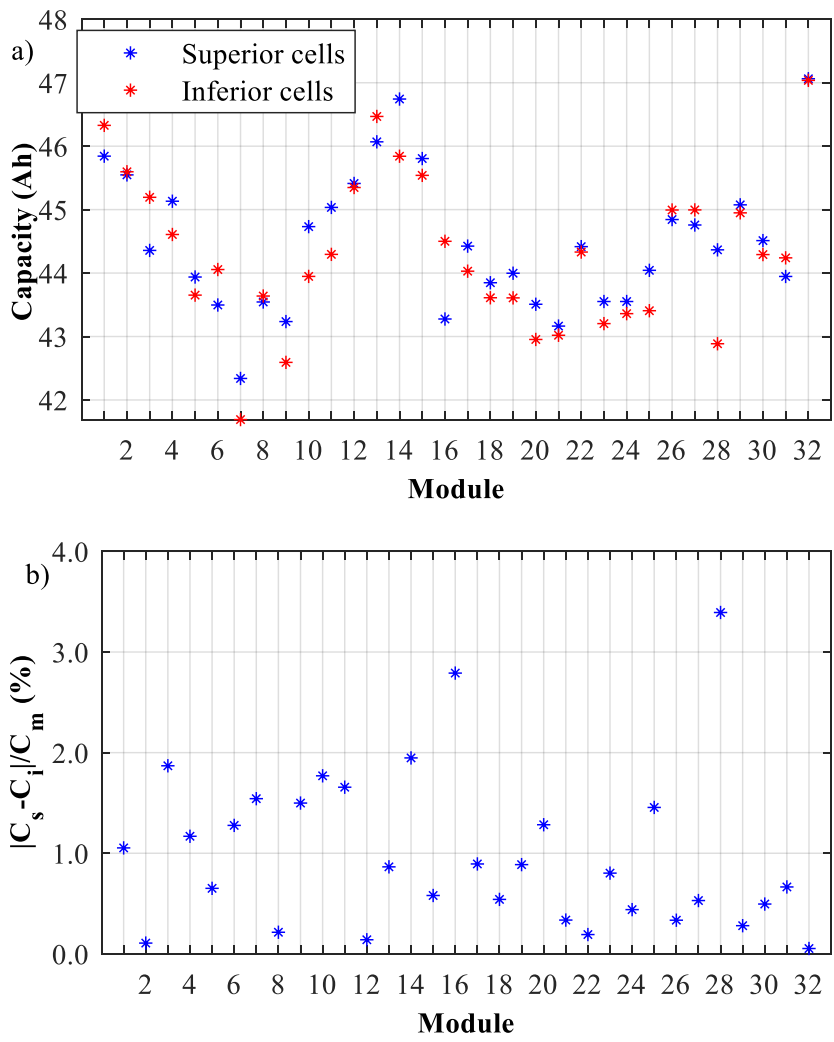

Fig. 7.a) Capacity measurements on superior and inferior cells and b) capacity differences between superior and inferior cells of 32 Nissan Leaf SL battery modules respect to the average capacity of the module. 

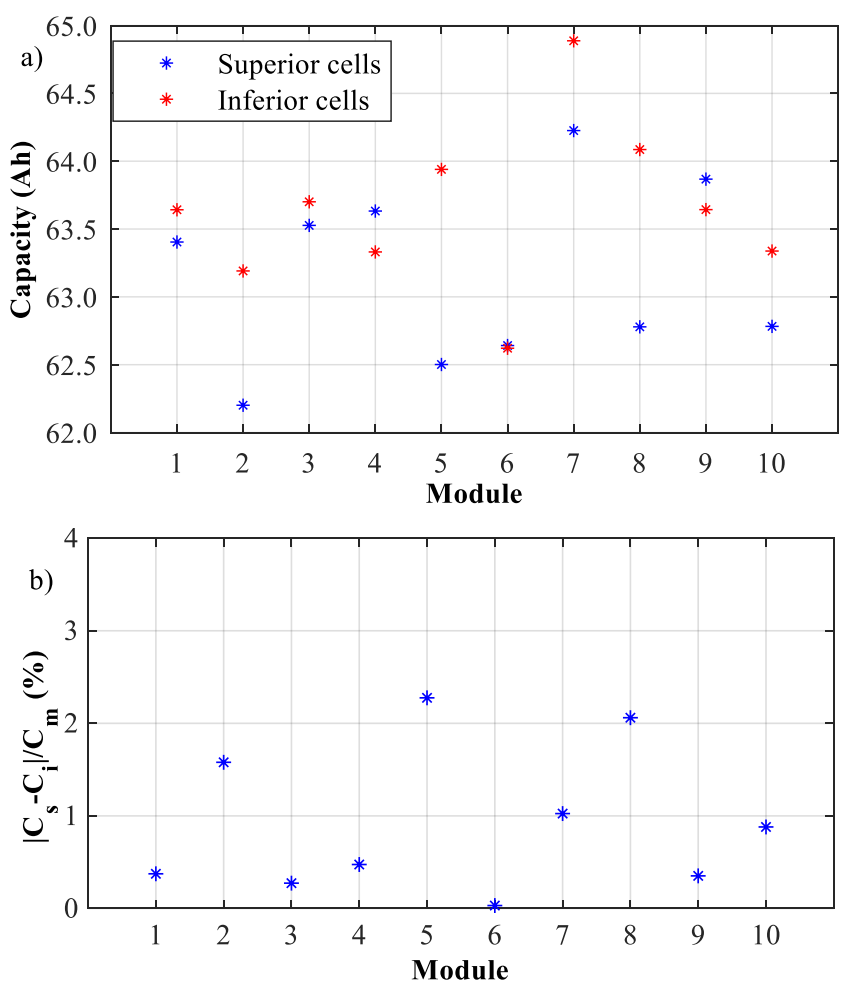

Fig. 8. a) Capacity measurements on superior and inferior cells and b) capacity differences between superior and inferior cells of 10 Nissan Leaf FL battery modules respect to the average capacity of the module.

Hence, Fig. 9 shows the capacity data of 32 SL modules. The average capacity value is $44.4 \mathrm{Ah}$, which corresponds to $68 \%$ with respect to the rated capacity of these samples. The maximum and minimum capacity values are $47 \mathrm{Ah}$ and $42 \mathrm{Ah}$, which implies a total difference of $11.3 \%$ of the average capacity. On the other hand, the capacity obtained on 10 FL Nissan Leaf modules is plotted in Fig. 10. The average capacity of these samples is $63.4 \mathrm{Ah}$, and the extreme values are 64.5 Ah and 62.6 Ah. The range is hence $3.0 \%$ of the average capacity. From the results obtained, it can be stated that the aging history of the modules in the EV affects greatly the initial state of their SL, and a proper characterization is thus necessary at the reconfiguration state.

\section{FL and SL batteries comparison}

As previously reported, cell and module dispersion has a negative impact on battery performance. Given that reconfiguration processes are usually expensive and complex, it is important to compare new and reused modules, so that technical

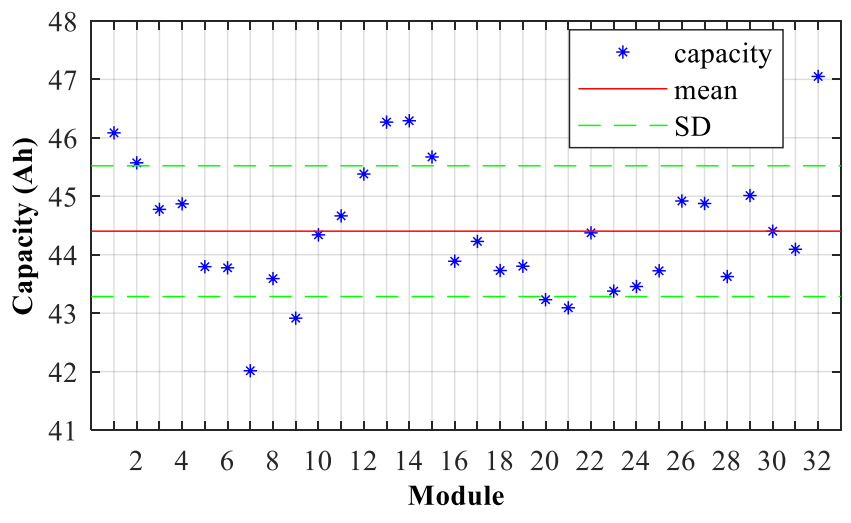

Fig. 9. Capacity of 32 Nissan Leaf SL battery modules.

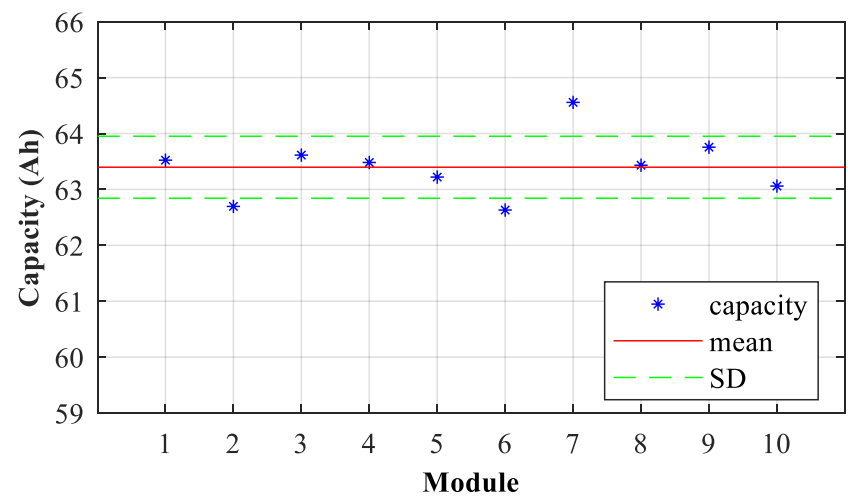

Fig. 10. Capacity of 10 Nissan Leaf FL battery modules.

limits and degradation effects can be distinguished. This subsection thus contrasts the impact of dispersion in FL and SL modules, being the main results presented in Table III.

Considering intra-module dispersion, its value is computed as the difference between superior and inferior cells with respect to the mean capacity of the module. Mean difference $\left(D_{\text {mean }}\right)$, maximum difference $\left(D_{\max }\right)$ and minimum difference $\left(D_{\min }\right)$ on the FL and SL modules are also presented. As it can be seen in the table, intra-module data are similar in FL and SL, with a $D_{\text {mean }}$ of $0.93 \%$ and $0.99 \%$ respectively. Maximum dispersion is slightly greater on the SL modules $(3.39 \%)$ with respect to the FL samples $(2.27 \%)$. These greater differences in SL modules could be related to unequal cell balancing processes during their usage in EVs.

On the other hand, in order to analyze the inter-module dispersion, mean capacity $\left(C_{\text {mean }}\right)$, standard deviation $(S D)$, coefficient of variation $\left(C V, C V=S D / C_{\text {mean }}\right)$ and range are computed, this last one as the difference between maximum and minimum capacity with respect to average capacity. Table III shows these values computed for FL and SL modules. As it can be observed, the inter-module dispersion between the SL samples is greater, with a difference of $11.3 \%$, while the FL modules differ by $3.0 \%$ among them. In this case, the EV usage could be determinant for the variations observed between new and reused modules. Environmental and usage differences among battery packs, as well as balancing variations could contribute to uneven aging rates of the modules, which result in a greater dispersion at the beginning of their SL.

In the light of these results, it can be argued that it is not worthwhile to disassemble the modules at cell level, given that

TABLE III. FL AND SL MODULES DISPERSION

\begin{tabular}{|c|c|c|}
\hline & SL modules & FL modules \\
\hline \multicolumn{3}{|c|}{ Intra-module dispersion } \\
\hline Dmean (\%) & 0.99 & 0.93 \\
\hline Dmax (\%) & 3.39 & 2.27 \\
\hline Dmin (\%) & 0.05 & 0.03 \\
\hline \multicolumn{2}{|c|}{ Inter-module dispersion } \\
\hline Cmean (Ah) & 44.4 & 63.4 \\
\hline SD (Ah) & 1.12 & 0.58 \\
\hline CV (\%) & 2.52 & 0.91 \\
\hline Range (Ah) & 5.04 & 1.92 \\
\hline Range /Cmean (\%) & 11.3 & 3.0 \\
\hline
\end{tabular}


the dispersion observed is similar in SL and new modules. The high cost of this procedure supports this hypothesis, leading therefore to the acceptance of this heterogeneity in the configuration of battery packs with both FL and SL modules. Conversely, in terms of inter-module analysis, capacity dispersion is nearly four times greater in reused modules than in new samples. The reconfiguration at module level is thus suggested to be a good option for SL batteries. Otherwise, the existing dispersion will affect negatively the performance of SL batteries if there is a random selection of modules. Moreover, the impact of these inhomogeneities will lead to the reduction of the economic viability on SL modules reutilization. Note that this analysis has been carried out in modules of a specific EV model, and general conclusions should be therefore carefully considered.

\section{AGING ANALYSIS}

As discussed in previous sections, the performance of SL modules is much more influenced by the operating conditions than in FL. Moreover, the capacity dispersion among modules is greater. Given the importance of assessing the technical performance of SL batteries, this section aims to deepen the aging analysis. For this purpose, 6 SL modules are cycled under the accelerated profile described in Section II. In order to extend previous conclusions of this contribution, the evolution of capacity and energy efficiency with time and the impact of aging on the SL performance will be examined, as well as the progression of dispersion.

\section{A. Capacity evolution}

As noted above, capacity measurements in SL modules are highly influenced by the operating conditions. Therefore, it is of great interest to assess the evolution of this parameter during SL. In this context, this subsection focuses on the experimental measurements of capacity under a prolonged aging test. Fig. 11 depicts the capacity measurements on the $6 \mathrm{SL}$ modules under accelerated aging at $25^{\circ} \mathrm{C}$ and $1 \mathrm{C}$ as charge and discharge rate. The results are referred to the rated capacity of the modules $\left(C_{n}\right)$. The number of cycles in the SL test is plotted in the $\mathrm{X}$ axis.

As it can be seen in the figure, capacity decreases with a linear trend in the initial stages of aging, which is consistent with the FL evolution reported from real Nissan Leaf data [37]. Note that the operating conditions in EVs and in the SL test of this contribution are different, and therefore the slopes of the linear stage could vary. The main aging mechanism associated to this linear capacity fade is the growth of the solid electrolyte interphase in the anode and the consequent loss of active $\mathrm{Li}$ [38], [39]. Moreover, the specific chemistry of the LMO cells

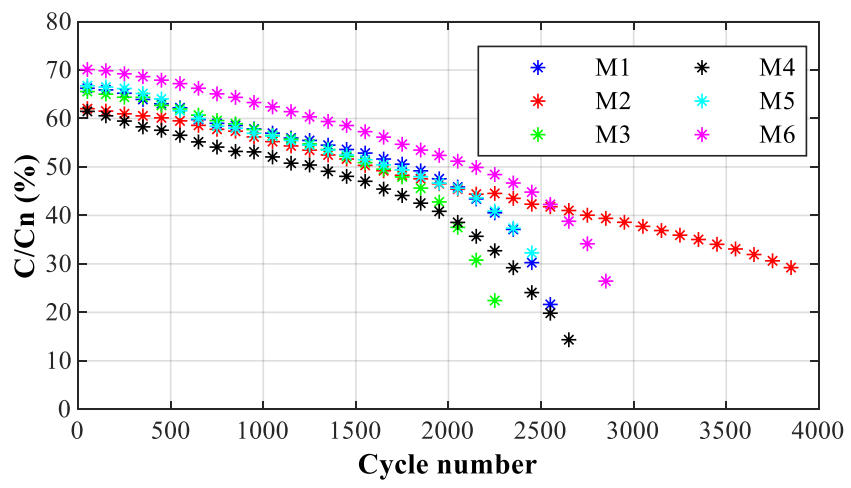

Fig. 11. Evolution of capacity vs. cycle number on $6 \mathrm{SL}$ module under cycling aging with discharge rate of $1 \mathrm{C}$ at $25^{\circ} \mathrm{C}$. entails degradation mechanisms such as Mn dissolution into the electrolyte [40], [41] or structural changes due to JahnTeller distortion [42], [43], both contributing to capacity fade and impedance increase, thereby reducing the performance of the cells.

Conversely, in advanced stages of the test, five out of the six SL modules experience a sudden decrease of capacity, which becomes nonlinear. This shift of trend is generally related to a change in the main aging mechanisms of the cells. Accelerated capacity loss is associated to several causes, such as the reduction of ion kinetics [39], [44], the loss of anode active material [39], [44], the increase of impedance in the positive electrode [45], or the deposition of metallic Li [34], [44], [46]. The operation in this area entails safety risks such as internal shortcircuits [47]. Thus, SL performance in real applications should be restricted to the linear part, and recent research contributions have suggested this turning point to determine the end of SL batteries lifetime [31], [32]. For the modules tested, this would correspond to 1875 to 2500 cycles. Nevertheless, one of the samples, M2, continues with a linear capacity fade trend after 3850 cycles. Even though this sample had one of the lowest capacities at the beginning of the test, it has shown the best results in terms of durability. The prediction of similar lifespan levels would be of great interest regarding the reconfiguration of reused modules, since it would reinforce the technical and economic viability of SL batteries. Therefore, other characterization techniques that deepen in the aging state, such as Incremental Capacity Analysis [25], could be considered for SL batteries. Note that the aging test is carried out under specific conditions and in a controlled environment, hence the extrapolation to a real SL application must be carefully considered.

\section{B. Energy efficiency evolution}

Being an indicator of the real performance of the module, energy efficiency is an interesting parameter to analyse in terms of aging. Therefore, this subsection aims to assess its evolution at different aging stages. For a given cycle, the energy efficiency is computed as explained in Section III. Fig. 12 shows the results from the measurements at $25^{\circ} \mathrm{C}$ and $1 \mathrm{C}$ on the $6 \mathrm{SL}$ modules. The $\mathrm{X}$ axis plots the total number of cycles.

During their aging, as it can be seen in the figure, the modules present different efficiency fade rates. On the one hand, on the early stages there is a limited efficiency loss. More precisely, the average value of this parameter decreases $3 \%$ after around 1500 cycles of SL test. This trend is accelerated between roughly 1500 and 2000 cycles, where $3 \%$ average efficiency loss is measured. The latter part of the test shows the

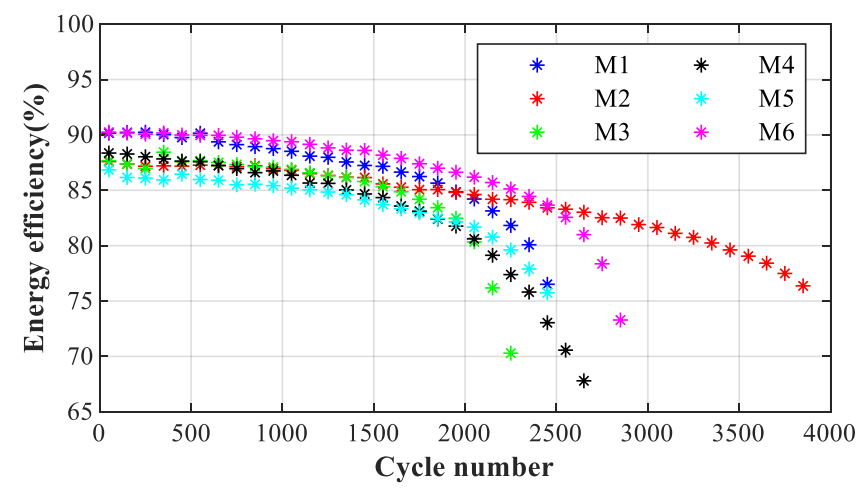

Fig. 12. Energy efficiency vs. cycle number on 6 SL modules under cycling aging with discharge rate of $1 \mathrm{C}$ at $25^{\circ} \mathrm{C}$. 
greatest efficiency fade, with an average of $22 \%$ between approximately 2000 and 2500 cycles. This is related with the acceleration of capacity fade rate, which, as shown in Fig. 11, occurs after between 1875 to 2500 test cycles. It should be considered that this analysis is performed at $1 \mathrm{C}$ and with $25^{\circ} \mathrm{C}$ as test temperature. Given the influence of temperature and current observed in Section III.A, the consequences of degradation in energy efficiency are expected to be much worse at lower temperatures

\section{Influence of aging on module performance}

The behavior of FL and SL modules under given operating conditions differs, as it is shown in Fig. 5. Besides having greater voltage drops, the SL module may also present a different voltage shape at low temperatures and high currents as a result of degradation. Given that voltage is usually chosen as a performance limit in real applications, this subsection is focused on the evolution of this parameter with aging. Fig. 13 plots the discharge voltage measured on one of the SL modules (M1) at different stages of aging versus the corresponding capacity measurements at these points.

As it can be observed, the voltage shape is similar at nearly all phases of aging, except at 2500 cycles. This general trend is similar to the one observed in Fig. 5 for the FL and SL module under the same operating conditions. Nevertheless, when it comes to advanced aging stages, such as the 2500 cycle measurement, voltage decreases with a greater slope and the module suffers an important capacity fade. This point occurs after the change of trend in capacity. Therefore, it can be stated that advanced degradation states affect negatively the performance of the module.

Assuming a real SL application with $3 \mathrm{~V}$ as cell cut-off discharge voltage, the energy delivered at 2500 cycles would be $59 \%$ lower than at 2000 cycles. Note that, from the behaviour observed in Fig. 5, the response of the SL module at low temperatures is much worse than at $25^{\circ} \mathrm{C}$, so the consequences of degradation in advanced stages of aging would be more severe.

\section{Dispersion analysis during aging}

Reused modules have greater inter-module heterogeneity than their fresh homologues, as discussed in Section IV. Given the importance of dispersion in real applications, this subsection aims to compare the evolution of the aging rates during SL. For this purpose, the aging data of the six SL modules are contrasted, and the inter-module dispersion in capacity is evaluated every 500 cycles. Table IV presents the main results of the analysis. Note that the tests are stopped in five of the modules after between 2250 and 2900 cycles, being thus 2500 the last point analyzed.

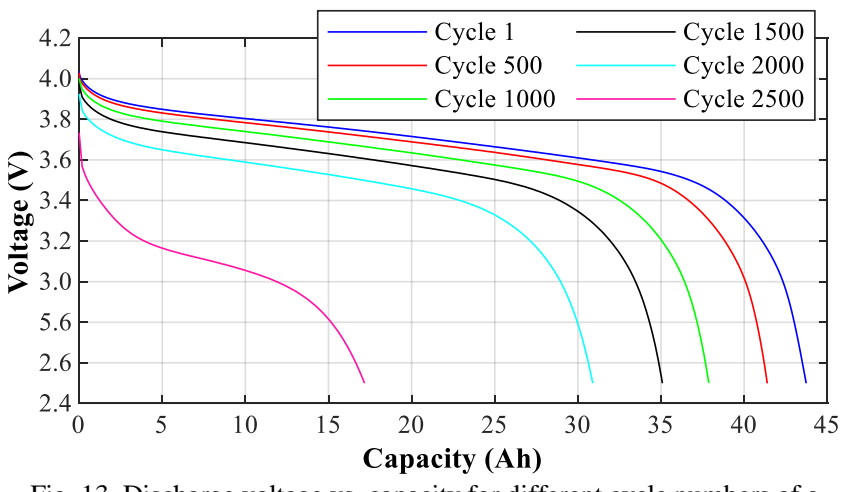

Fig. 13. Discharge voltage vs. capacity for different cycle numbers of a SL module under cycling aging with discharge rate of $1 \mathrm{C}$ at $25^{\circ} \mathrm{C}$.
TABLE IV. SL INTER-MODULE DISPERSION DURING AGIING

\begin{tabular}{|c|c|c|c|c|c|c|}
\hline Cycle number & $\mathbf{0}$ & $\mathbf{5 0 0}$ & $\mathbf{1 0 0 0}$ & $\mathbf{1 5 0 0}$ & $\mathbf{2 0 0 0}$ & $\mathbf{2 5 0 0}$ \\
\hline Cmean $(\mathrm{Ah})$ & 44.1 & 41.9 & 38.9 & 36.3 & 32.6 & 26.0 \\
\hline SD (Ah) & 2.07 & 2.32 & 2.06 & 1.89 & 2.11 & 4.78 \\
\hline CV (\%) & 4.71 & 5.53 & 5.30 & 5.21 & 6.49 & 10.44 \\
\hline Range (Ah) & 5.57 & 6.93 & 6.17 & 5.54 & 5.60 & 18.41 \\
\hline Range /Cmean (\%) & 12.6 & 16.5 & 15.8 & 15.3 & 17.2 & 40.2 \\
\hline
\end{tabular}

As it can be seen in the table, the capacity dispersion between modules undergoes an initial increase up to $16.5 \%$ after 500 cycles, which could be related to the differences in performance after a resting period from their extraction from the EVs to the beginning of the SL test. On a second stage, capacity dispersion remains stable during 1500 cycles. This would correspond to a homogeneous capacity fade trend in all the modules, which, according to Fig. 11, is associated with the linear part of the capacity curve. Finally, in the latter stages of the aging test, an increase of capacity dispersion up to $40 \%$ is observed. This increase corresponds to the change of trend in capacity, which was detected in five out of the six SL modules tested after between 1875 and 2550 cycles. Note that M3 reached the end of test after 2250 cycles and therefore it is not considered in the dispersion analysis at this last point.

All in all, regarding the inter-module dispersion analysis presented in Table IV, it can be stated that dispersion is aggravated in SL especially after the capacity fade change of trend. Given that capacity differences are similar during most of the SL test, the adequate selection of modules with similar capacity values at the reconfiguration stage would be highly advisable.

\section{CONCLUSION}

This paper presents an experimental technical assessment of new and reused modules from the Nissan Leaf EV. The analysis covers three main aspects: performance, capacity dispersion and extended SL behavior.

Regarding performance, characterization test results show that temperature has greater influence than discharge current on capacity measurements of SL modules. Compared to similar measures in new modules, temperature is found to have six times more impact in SL, while the influence of discharge current is up to nine times greater. Conversely, both current and temperature have similar impact in energy efficiency measurements of SL modules, which is more than four times greater than in FL. The impact of module degradation on its performance is found to be especially important at high currents and low temperatures, which would entail up to $76 \%$ of energy loss in a real application scenario. Therefore, we encourage the revision of the operation limits of SL batteries for each chemistry and technology. For the modules under test, we would strongly recommend operation temperatures around $25^{\circ} \mathrm{C}$, and the limitation of upper current ranges if low operation temperatures were expected.

In what capacity dispersion concerns, the study is carried out with 32 SL and 10 FL modules. The analysis is firstly referred to the existing dispersion inside the modules (intramodule) and, in a second step, to the differences among modules (inter-module). Results show that the intra-module dispersion is similar and not significant in both module types. By contrast, the inter-module variations observed are almost four 
times greater in SL modules. The reconfiguration at module level is thus suggested for Nissan Leaf battery packs, so that the impact of dispersion in the reconfigured battery can be damped. Thereby, SL battery lifetime would be enhanced, ensuring their economic viability.

The third main contribution of this paper is the experimental assessment of second-life aging, by evaluating performance and dispersion of 6 reused modules. Under an accelerated cycling profile at $25^{\circ} \mathrm{C}$ and $1 \mathrm{C}$, capacity initially fades with a linear trend, and in a second stage with an accelerated loss rate. The impact of degradation in this latter stage of aging is also observed in energy efficiency, voltage shape and dispersion. The results obtained in this test, together with the safety risks reported in literature, discourage the operation of SL modules once they suffer accelerated degradation. Nevertheless, we can state that SL modules operate successfully below the $80 \%$ capacity limit of automotive standards. The great differences observed in the number of cycles performed before the turning point in the aging rate are a promising result for the viability of these batteries, as well as a challenge to identify this shift in real applications.

All in all, this contribution highlights that the correct use of retired modules from EVs to reconfigure SL batteries requires an adequate characterization. The main reasons are their significantly different behaviour with respect to new modules and the greater dispersion among them. Moreover, the performance of these modules is confirmed to be strongly degraded at latter stages of aging. Given the current challenges when it comes to assess SL EVBs behavior, a tracking of the operating conditions during their automotive use is highly encouraged. The technical potential of reused modules should be accompanied by significantly lower costs than new batteries, so that their integration in stationary applications will become a reality.

\section{REFERENCES}

[1] International Energy Agency, "Global EV Outlook 2019," Paris, 2019.

[2] IEC, "IEC 62660 - 1: Secondary lithium-ion cells for the propulsion of electric road vehicles - Part 1: Performance testing." 2010.

[3] J. P. Christophersen, "Battery Test Manual For Electric Vehicles, Revision 3," no. June, 2015.

[4] A. P. J. Neubauer, K. Smith, E. Wood, "Identifying and Overcoming Critical Barriers to Widespread Second Use of PEV Batteries," Natl. Renew. Energy Lab., no. February, pp. 23-62, 2015.

[5] U. K. Debnath, I. Ahmad, and D. Habibi, "Quantifying economic benefits of second life batteries of gridable vehicles in the smart grid," Int. J. Electr. Power Energy Syst., vol. 63, pp. 577-587, 2014.

[6] E. Hossain, D. Murtaugh, J. Mody, H. M. R. Faruque, M. S. H. Sunny, and N. Mohammad, "A Comprehensive Review on Second-Life Batteries: Current State, Manufacturing Considerations, Applications, Impacts, Barriers Potential Solutions, Business Strategies, and Policies," IEEE Access, vol. 7, no. c, pp. 73215-73252, 2019.

[7] R. Reinhardt, I. Christodoulou, S. Gassó-Domingo, and B. Amante García, "Towards sustainable business models for electric vehicle battery second use: A critical review," J. Environ. Manage., vol. 245, no. December 2018, pp. 432-446, 2019.

[8] E. Martinez-Laserna et al., "Battery second life: Hype, hope or reality? A critical review of the state of the art," Renew. Sustain. Energy Rev., vol. 93, no. February 2017, pp. 701-718, 2018.

[9] Nissan and Eaton, "Energy storage for Buildings : designed and built for sustainability and resilience," 2017.

[10] B. Gohla-Neudecker, M. Bowler, and S. Mohr, "Battery 2nd life: Leveraging the sustainability potential of EVs and renewable energy grid integration," 5th Int. Conf. Clean Electr. Power Renew. Energy
Resour. Impact, ICCEP 2015, pp. 311-318, 2015.

[11] Daimler AG, "World's largest 2nd-use battery storage is starting up," pp. 1-2, 2016.

[12] A. Podias et al., "Sustainability assessment of second use applications of automotive batteries: Ageing of Li-ion battery cells in automotive and grid-scale applications," World Electr. Veh. J., vol. 9, no. 2, 2018.

[13] A. Berrueta, J. Pascual, I. San Martín, P. Sanchis, and A. Ursua, "Influence of the Aging Model of Lithium-Ion Batteries on the Management of PV Self-Consumption Systems," Proc. - 2018 IEEE Int. Conf. Environ. Electr. Eng. 2018 IEEE Ind. Commer. Power Syst. Eur. EEEIC/I CPS Eur. 2018, 2018.

[14] I. San Martín, A. Berrueta, P. Sanchis, and A. Ursúa, "Methodology for sizing stand-alone hybrid systems: A case study of a traffic control system," Energy, vol. 153, pp. 870-881, 2018.

[15] A. Berrueta, I. San Martín, P. Sanchis, and A. Ursúa, "Comparison of State-of-Charge estimation methods for stationary Lithium-ion batteries," IECON Proc. (Industrial Electron. Conf., pp. 2010-2015, 2016.

[16] A. Berrueta, A. Urtasun, A. Ursúa, and P. Sanchis, "A comprehensive model for lithium-ion batteries: From the physical principles to an electrical model," Energy, vol. 144, pp. 286-300, 2018.

[17] C. Curry, "Lithium-ion Battery Costs and Market, BNEF, 5 July 2017," 2017.

[18] S. Rohr et al., "Quantifying Uncertainties in Reusing Lithium-Ion Batteries from Electric Vehicles," Procedia Manuf., vol. 8, no. October 2016, pp. 603-610, 2017.

[19] S. Jinlei, P. Lei, L. Ruihang, M. Qian, T. Chuanyu, and W. Tianru, "Economic Operation Optimization for 2nd Use Batteries in Battery Energy Storage Systems," IEEE Access, vol. 7, pp. 41852-41859, 2019.

[20] C. Bas Domenech and M. Heleno, "Comparing Values of Second Life Batteries to Different Classes of Prosumers in California," in 2019 IEEE Green Technologies Conference(GreenTech), 2019, no. 2, pp. $1-4$.

[21] A. Saez-de-Ibarra, E. Martinez-laserna, D. Stroe, M. Swierczynski, and P. Rodriguez, "Sizing Study of Second Life Li-ion Batteries for Enhancing Renewable Energy Grid Integration," IEEE Trans. Ind. Appl., vol. 52, no. 6, pp. 4999-5008, 2016.

[22] H. Li, M. Alsolami, S. Yang, Y. M. Alsmadi, and J. Wang, "Lifetime Test Design for Second-Use Electric Vehicle Batteries in Residential Applications," IEEE Trans. Sustain. Energy, vol. 8, no. 4, pp. 17361746, 2017.

[23] T. Alharbi, K. Bhattacharya, and M. Kazerani, "Planning and Operation of Isolated Microgrids Based on Repurposed Electric Vehicle Batteries," IEEE Trans. Ind. Informatics, vol. 15, no. 7, pp. 4319-4331, 2019.

[24] M. Baumann, L. Wildfeuer, S. Rohr, and M. Lienkamp, "Parameter variations within Li-Ion battery packs - Theoretical investigations and experimental quantification,” J. Energy Storage, vol. 18, no. April, pp. 295-307, 2018.

[25] Y. Jiang, J. Jiang, C. Zhang, W. Zhang, Y. Gao, and Q. Guo, "Recognition of battery aging variations for $\mathrm{LiFePO} 4$ batteries in 2nd use applications combining incremental capacity analysis and statistical approaches," J. Power Sources, vol. 360, pp. 180-188, 2017.

[26] S. F. Schuster, M. J. Brand, P. Berg, M. Gleissenberger, and A. Jossen, "Lithium-ion cell-to-cell variation during battery electric vehicle operation," J. Power Sources, vol. 297, pp. 242-251, 2015.

[27] J. Kim and B. H. Cho, "Screening process-based modeling of the multi-cell battery string in series and parallel connections for high accuracy state-of-charge estimation," Energy, vol. 57, pp. 581-599, 2013.

[28] A. Berrueta, I. S. Martin, J. Pascual, P. Sanchis, and A. Ursua, "On the requirements of the power converter for second-life lithium-ion batteries," in 2019 21st European Conference on Power Electronics and Applications, EPE 2019 ECCE Europe, 2019.

[29] R. Gogoana, M. B. Pinson, M. Z. Bazant, and S. E. Sarma, "Internal resistance matching for parallel-connected lithium-ion cells and impacts on battery pack cycle life," J. Power Sources, vol. 252, pp. 8- 
$13,2014$.

[30] X. Gong, R. Xiong, and C. C. Mi, "Study of the Characteristics of Battery Packs in Electric Vehicles with Parallel-Connected LithiumIon Battery Cells," IEEE Trans. Ind. Appl., vol. 51, no. 2, pp. $1872-$ 1879, 2015.

[31] E. Martinez-Laserna et al., "Technical Viability of Battery Second Life: A Study from the Ageing Perspective," IEEE Trans. Ind. Appl., vol. 54, no. 3, pp. 2703-2713, 2018.

[32] E. Braco, I. San Martín, A. Berrueta, P. Sanchis, and A. Ursúa, "Experimental assessment of cycling ageing of lithium-ion secondlife batteries from electric vehicles," J. Energy Storage, vol. 32, no. July, p. 101695, 2020.

[33] E. Braco, I. San Martín, P. Sanchis, and A. Ursua, "Characterization and capacity dispersion of lithiumion second-life batteries from electric vehicles," 2019 IEEE Int. Conf. Environ. Electr. Eng. 2019 IEEE Ind. Commer. Power Syst. Eur. (EEEIC / I\&CPS Eur., pp. 1-6, 2019.

[34] T. Waldmann, B. I. Hogg, and M. Wohlfahrt-Mehrens, "Li plating as unwanted side reaction in commercial Li-ion cells - A review," $J$. Power Sources, vol. 384, no. November 2017, pp. 107-124, 2018.

[35] Y. Ji, Y. Zhang, and C.-Y. Wang, "Li-Ion Cell Operation at Low Temperatures," J. Electrochem. Soc., vol. 160, no. 4, pp. A636-A649, 2013.

[36] A. Barai, K. Uddin, W. D. Widanalage, A. McGordon, and P. Jennings, "The effect of average cycling current on total energy of lithium-ion batteries for electric vehicles," J. Power Sources, vol. 303, pp. 81-85, 2016.

[37] D. Myall, D. Ivanov, W. Larason, M. Nixon, and H. Moller, "Accelerated reported battery capacity loss in $30 \mathrm{kWh}$ variants of the Nissan Leaf," Preprints, no. March. 2018.

[38] D. A. Stevens, R. Y. Ying, R. Fathi, J. N. Reimers, J. E. Harlow, and J. R. Dahn, "Using High Precision Coulometry Measurements to Compare the Degradation Mechanisms of NMC/LMO and NMC-
Only Automotive Scale Pouch Cells," J. Electrochem. Soc., vol. 161, no. 9, pp. A1364-A1370, 2014.

[39] J. C. Burns et al., "Predicting and Extending the Lifetime of Li-Ion Batteries," J. Electrochem. Soc., vol. 160, no. 9, pp. A1451-A1456, 2013.

[40] Y. Dai, L. Cai, and R. E. White, " Capacity Fade Model for Spinel LiMn 2 O 4 Electrode ," J. Electrochem. Soc., vol. 160, no. 1, pp. A182-A190, 2013.

[41] D. H. Jang, Y. J. Shin, and S. M. Oh, "Dissolution of Spinel Oxides and Capacity Losses in $4 \mathrm{~V} \mathrm{Li} / \mathrm{Li} x \mathrm{Mn} 2 \mathrm{O} 4$ Cells," J. Electrochem. Soc., vol. 143, no. 7, pp. 2204-2211, 1996.

[42] R. J. Lancashire, “The Jahn-Teller Theorem," University of the West Indies, Jamaica, 1995. [Online]. Available: http://wwwchem.uwimona.edu.jm/courses/JahnTeller.html.

[43] K. Y. Chung, C.-W. Ryu, and K.-B. Kim, "Onset Mechanism of JahnTeller Distortion in $4 \mathrm{~V} \mathrm{LiMn[sub} \mathrm{2]O[sub} \mathrm{4]} \mathrm{and} \mathrm{Its} \mathrm{Suppression} \mathrm{by}$ LiM[sub 0.05] Mn[sub 1.95] O[sub 4] (M = Co, Ni) Coating," $J$. Electrochem. Soc., vol. 152, no. 4, p. A791, 2005.

[44] S. F. Schuster et al., "Nonlinear aging characteristics of lithium-ion cells under different operational conditions," J. Energy Storage, vol. 1, no. 1, pp. 44-53, 2015.

[45] X. Ma et al., "Hindering Rollover Failure of Li[Ni 0.5 Mn 0.3 Co 0.2 ]O 2 /Graphite Pouch Cells during Long-Term Cycling," $J$. Electrochem. Soc., vol. 166, no. 4, pp. A711-A724, 2019.

[46] L. E. Downie, L. J. Krause, J. C. Burns, L. D. Jensen, V. L. Chevrier, and J. R. Dahn, "In Situ Detection of Lithium Plating on Graphite Electrodes by Electrochemical Calorimetry," J. Electrochem. Soc., vol. 160, no. 4, pp. A588-A594, 2013.

[47] J. Wen, Y. Yu, and C. Chen, "A review on lithium-ion batteries safety issues: Existing problems and possible solutions," Mater. Express, vol. 2, no. 3, pp. 197-212, 2012. 